\title{
POÉTICAS DA REBELDIA: \\ A DRAMATURGIA DE PLÍNIO MARCOS E O PENSAMENTO DE ANTONIN ARTAUD
}

\section{Poetics of rebellion: the dramaturgy of Plínio Marcos and the thought of Antonin Artaud}

\author{
Gessé Almeida Araújo \\ Universidade Federal do Sul da Bahia - UFSB
}

Resumo: O presente artigo aproxima a dramaturgia de Plínio Marcos do pensamento do encenador francês Antonin Artaud. O naturalismo tardio de Plínio Marcos integrou-se com o momento político que o Brasil viveu antes e depois do golpe de 1964. Os principais fundamentos do Teatro da Crueldade calçam a aproximação entre as visadas sobre a arte da representação, como fundamentos do que se chama de poéticas da rebeldia.

Palavras-chave: Artes do espetáculo; Plínio Marcos; Antonin Artaud; Poética; Rebeldia.

Abstract: This article approaches Plínio Marcos's dramaturgy from the thought of the French director Antonin Artaud. The late-born naturalism of Plínio Marcos integrated with the political moment that Brazil lived before and after the coup of 1964. The main foundations of the Theater of Cruelty give way to the approximation between the visions on the art of representation, as foundations of what is called the poetics of rebellion.

Keywords: Performing Arts; Plínio Marcos; Antonin Artaud; Poetic; Rebellion. 
Tenho dedicado as minhas últimas pesquisas ao aprofundamento do que considero como sendo uma poética própria dentro do conjunto dramatúrgico de autoria do santista Plínio Marcos de Barros (19351999). Trata-se de um arranjo poético cuja principal característica é uma produção que tem no constante desafio às forças morais e políticas de seu tempo, o seu principal intento. Para fins deste artigo serão consideradas como pertencentes à poética da rebeldia as peças do dramaturgo santista escritas entre 1958 e 1969, que resguardam as contribuições específicas deste autor para 0 teatro brasileiro moderno: Barrela (1958), Chapéu sobre paralelepípedo para alguém chutar (1965), Reportagem de um tempo mau (1965), Navalha na carne (1967), Dois perdidos numa noite suja (1966), Quando as máquinas param (1967), cuja primeira versão chama-se Enquanto os navios atracam, de 1963, Oração para um pé de chinelo (1967), Homens de papel (1968), Querô, uma reportagem maldita (1976), Abajur lilás (1969). Estas obras resguardam as características de um naturalismo tardio no teatro brasileiro, sendo recorrente o uso de uma linguagem de forte impacto e os enredos de figuras marginalizadas dos tecidos urbanos.

A poética da rebeldia encontra reverberação em diversos outros discursos e práticas artísticas, notadamente em determinados artistas que, a exemplo de Plínio Marcos, concebiam o teatro como sendo um espaço privilegiado de ação tanto na sociedade de modo geral, quanto no desejo de uma reivindicação dentro do seu campo de atuação. As abordagens do encenador francês Antonin Artaud e suas teorizações em torno do seu "teatro da crueldade" dispararam sobre o universo criador de diversos artistas, ferramentas que ajudaram algumas práticas teatrais a responder no campo estético aos paradigmas de um mundo contraditório, uma linha de ação marcadamente ideológica. Como é notório, Plínio Marcos e Artaud não conceberam seus trabalhos de modo semelhante. O primeiro talvez sequer tenha aprofundado estudos na obra do segundo. Entretanto, há elementos da composição de teatro no viés artaudiano que encontra no teatro de Plínio Marcos e, sobretudo na poética rebelde, aproximações possíveis numa coerência ideológica que somente uma sintonia no nível da interpretação do espírito do tempo pode promover.

O princípio básico do teatro de ambos, reservadas as devidas diferenças, pode ser compreendido como sendo a crítica a seu tempo, em base estética que propunha formas de composição teatral que correspondessem aos anseios históricos do presente na França da primeira metade do século XX e no Brasil da segunda metade do mesmo século. Há nessa correspondência o entendimento de que a cultura, o teatro e a vida não deveriam ser concebidos em separado, mas sendo a cultura um campo de observação social, se transmuta em um modo de exercer a vida, como sugere Artaud (2006). Os tempos históricos em que ambos viveram foram marcados por um sem números de eventos que promoveram rupturas deixando marcas que conhecemos até o presente inúmeras no campo das artes. A censura, por exemplo, velada ou empenhada pelo Estado, foi durante quase a totalidade do 
século XX uma ação cuja base era sustentada por ações que circulavam entre a sociedade civil (que muitas vezes desejou a coerção no campo da cultura) até o poder institucional, nesse caso manifestado pelos regimes políticos autoritários ou não - que as sociedades conseguiram estabelecer. Como prática que com o passar dos anos adquiriu força de aparato policial, um dos perigos a ela relacionados está no fato de que para ser exercida, não deve mostrar suas verdadeiras feições resguardando por debaixo de um véu, ares de uma suposta legalidade. Este é o preço que se paga pelo desprezo à liberdade de pensamento e de criação.

O esforço de aproximação efetuado aqui entre as poéticas artaudianas e plinianas encontra ecos nos aspectos filosóficos da poética da rebeldia e sua reverberação no nível estético. Levando-se em consideração a leitura dos tempos históricos e levando-se em conta, também, o ideal de Artaud, "o espírito" - do tempo "necessita de uma linguagem para produzir suas manifestações" (2006, p.7). Na conjuntura geracional na qual Plínio Marcos se destacou como dramaturgo e os eventos históricos dos anos de 1960, a citada "linguagem" é a poética da rebeldia. Nela, Plínio Marcos serviu-se de ferramentas para conseguir manifestar sua visão a respeito da sociedade e do teatro de seu tempo. É uma evidência desse fato a busca das personagens marginalizadas, a procura da palavra em sua forma coloquial em nível extremo, bem como os enredos que fundaram um naturalismo tardio na moderna dramaturgia brasileira. Esses elementos concatenaram a busca de uma linguagem para 0 espírito de seu tempo, marcado pelo autoritarismo e pela indiferença no nível social. É a partir desses elementos, que Plínio Marcos constrói a "fisionomia espiritual de um mal que corrói o organismo e a vida até a ruptura e o espasmo" (ARTAUD, 2006, p.18), que se fundamenta a partir de uma leitura da vida de uma parcela da população vilipendiada diante do olhar dos poderes públicos de seu tempo.

O teatro de Plínio Marcos busca na manifestação enquanto "força de uma epidemia", um fundamento que torne sua concepção dramatúrgica compreendida e coerentemente interpretada por sua geração. A força do teatro, nesse caso, pode ser comparada à peste, pela sua ação capaz de matar sem destruir, pelo fato de provocar nos espíritos as alterações necessárias para que novas formas de visão se estabelecessem (ARTAUD, 2006, p.22). A proposição da poética da rebeldia tem como fundamento, o teatro em seu viés insubmisso, buscando atingir os corpos e também os costumes das plateias (ARTAUD, 2006, p.22), notadamente aquelas mais fortemente apegadas a visões de mundo passivas e indiferentes. Essa pode ser considerada uma vertente de teatro subversivo, elemento que a ditadura militar brasileira soube identificar no conjunto das obras de Plínio Marcos.

A metáfora da peste, preconizada por Artaud (2006), serve à poética da rebeldia como imagem que sugere uma ação de 
natureza desobediente. $\mathrm{O}$ ideal da referida poética, tal qual a peste é, em algum nível, sugerir algo às plateias de teatro, agindo sobre as coletividades, transformando-as. Em termos artaudianos, isso significa incendiar o pensamento e a ação do público de teatro, visando algum nível de transformação social, isto é, o distanciamento do que pode representar apego ao que é sinônimo de letargia - em todos os níveis da esfera da vida, inclusive em termos sociais e estéticos. É partir desse front estético que a poética da rebeldia estabelece-se, fazendo do teatro mais do que um elemento de entretenimento, uma ágora capaz de enxergar a condição humana - suas mazelas e, às vezes, suas grandezas - $\mathrm{e}$, com isso, gerar uma qualidade no nível da perturbação dos sentidos. $\mathrm{Em}$ outros termos, a poética da rebeldia atua, em certo nível, em transtornar as inteligências, fazendo-as reagir - pela repulsa ou pela paulatina compreensão - aos estímulos apresentados por uma obra encenada ou textualmente inscrita.

O teatro que se produziu no Brasil dos anos de 1960 carregava um elemento de didatismo que compunha a própria forma do teatro demonstrada por uma geração de artistas fortemente marcada por mudanças políticas, geração esta que trouxe em seu bojo o desejo de constituir uma sociedade mais justa. A poética da rebeldia resguarda em si determinados elementos didáticos uma vez que pretende promover algum nível de articulação na transformação das mentalidades. É evidente que a suposta didática pliniana era diferente daquela preconizada, por exemplo, pelo Teatro de Arena de São Paulo e seus expoentes
Augusto Boal, Oduvaldo Viana Filho e Gianfrancesco Guarnieri. A principal diferença entre ambos está exatamente no desejo do nível da perturbação mental que a poética da rebeldia, seus enredos, suas personagens e sua linguagem pretendiam atingir.

O desejo mais imediato da referida poética é o de retirar do estado de repouso os sentidos, liberando "o inconsciente comprimido", levando "a uma espécie de revolta virtual" e impondo "às coletividades reunidas uma atitude heroica e difícil" (ARTAUD, 2006, p.24). Essa espécie de didática pela peste pode ser compreendida como sendo fundamental para a composição de uma poética em seu viés rebelde. Nesse sentido, a peste torna-se ferramenta de algum tipo de ensinamento na medida em que ela se torna capaz de revelar à própria sociedade o seu lado mais abjeto, reles, podre, cruel, características que pertencem, em maior ou menor medida, a todo o corpo social (ARTAUD, 2006, p.27). O exercício poético em questão é 0 de apontar o espelho às plateias de teatro, fazendo-as compreender em que lugar estão e, com isso, afirmando a mais profunda perversidade alojada nos espíritos. A perversidade no nível humano é fruto de uma sociedade que carrega como verdades absolutas as mais obtusas compreensões do mundo, pouco afeitas a enxergar os demais sujeitos, sobretudo aqueles distanciados pelas condições econômicas como cidadania qualificada. A revelação das mazelas humanas, do modo como a poética da rebeldia pretende, pode ser um elemento de perspectiva social capaz de, a partir do desnudamento das verdades absolutas dos indivíduos e do 
corpo social, fazer enxergar a crueldade palavra cara à Artaud - presente no comportamento mais cotidiano de cada um e de cada uma. Portanto, a poética da rebeldia acaba por assimilar, com o intuito de pôr em evidência, as contradições da vida cotidiana e seus hábitos, seus modos de vida. A crueldade se manifesta por um efeito provocado pela vida em si, dentro do modo como nos foi possível, como humanidade, manifestá-la. Nesse bojo, o teatro que se pretenda reflexivo e gerador de uma ação rebelde concreta, ganha condições de se manifestar frente a um estado de coisas que solicita a ação estética e política conscientes.

Enxergar-se como um ser rebelde, cujo fim é a ação política consequente é uma prerrogativa do teatro de Plínio Marcos e sua poética. A metáfora artaudiana, segundo a qual através da peste, pelo teatro, um imenso abscesso "tanto moral quanto social" pode ser aberto coletivamente, torna-se chave de leitura da poética que abordo; a prerrogativa de Artaud é uma condição à própria existência do teatro (ARTAUD, 2006, p.28). É nesse sentido que a poética da rebeldia pode ser lida como um desvelamento de máscaras coletivas, usadas como dissimulação de escrúpulos de cidadania, falseados pelo maniqueísmo social incoerente entre prática e discurso. Nos termos de Artaud (2006),

[...] o teatro é um mal porque é o equilíbrio supremo que não se adquire sem destruição. Ele convida o espírito a um delírio que exalta suas energias; e para terminar pode-se observar que, do ponto de vista humano, a ação do teatro, como a da peste, é benfazeja pois, levando os homens a se verem como são, faz cair a máscara, põe a descoberta a mentira, a tibieza, a baixeza, o engodo; sacode a inércia asfixiante da matéria que atinge até os dados mais claros dos sentidos; e revelando para coletividades o poder obscuro delas, sua força oculta, convida-as a assumir diante do destino uma atitude heroica e superior que, sem isso, nunca assumiriam. (ARTAUD, 2006, p. 28-29)

Artaud (2006) disserta sobre seu modo de conceber o teatro dentro de uma época e de uma sociedade cujas características desqualificavam o debate em termos da reflexão do campo social e dos desafios na mudança de perspectiva $(2006$, p.41). O questionamento de uma suposta moral estabelecida e, também, do sistema social em vigor, foi pouco problematizado pelo teatro de seu tempo. O pensamento de Artaud, assim, toma corpo a partir da compreensão desta realidade e da sua problematização como sendo parte da tarefa do teatro. Nesse fato, reside mais uma aproximação possível com a dramaturgia de Plínio Marcos que, a exemplo do encenador francês, concebeu sua forma preferencial de abordagem dramatúrgica tendo um alvo social, bem como uma compreensão do papel do teatro no contexto das produções dos anos de 1960 e 1970, entre São Paulo e Rio de Janeiro.

A poética da rebeldia no teatro de Plínio Marcos é aquela que se confunde com a de outros artistas de seu tempo, acusados a seus turnos, de paternalismo e excessivo 
didatismo em suas produções teatrais. $O$ teatro desenvolvido pela geração pliniana tinha por intuito definido promover reflexão com vias a uma mudança real das bases de uma sociedade injusta. $O$ excesso de didatismo referido é real e esteve bastante em voga no seu tempo. Entretanto, diante de um regime ditatorial e com o desenho bem definido dos inimigos do teatro, a ação deveria ser igualmente bem desenhada, definida e direta. Se o ocidente se apresenta como sendo o "lugar por excelência onde se pôde confundir a arte com estetismo" (ARTAUD, 2006, p.77), um teatro confrontado com 0 autoritarismo deveria, por seu turno, reagir com estratégias de conquista de espaço que, aos olhos críticos legados do afastamento histórico, pode ser considerado didático e paternalista. Destarte, "a enfermidade espiritual" desse teatro poderia ter sido a omissão diante dos problemas que o teatro da época enfrentava, principalmente os referentes às liberdades individuais, de expressão e de criação, além da falta de liberdade política e seus desdobramentos.

Embora houvesse um esforço efetivo no sentido de comunicar a mensagem preconizada pelo teatro engajado dos anos de 1960, sua ação se manteve restrita a um pequeno grupo de classe média mais sensível ao debate política da esquerda de então. Salvo algumas experiências que conseguiram romper barreiras de classe, 0 teatro, mesmo o de Plínio Marcos, manteve-se como possibilidade de formação intelectual para uma pequena parcela da população já formada e com posicionamento político mais ou menos evidente. Por outro lado, é inegável que esta geração realizou o convite - a esta parcela privilegiada de público - a refletir sobre as situações que afetavam o país no campo social e político. $O$ convite à reação é uma prerrogativa de um tempo em que resistir poderia significar a possibilidade de tortura e morte pelo regime ditatorial. Isto posto, é possível associar muitas limitações ao engajamento do teatro nas décadas de 1960, exceto a omissão na busca de modos de conceber 0 teatro politicamente consequente.

O engajamento da poética da rebeldia está baseado na compreensão da prática teatral como exercício tanto para quem vê como para quem assiste. Ser cruel, na visada artaudiana, significa ser cruel consigo, com consciência do que a crueldade pode representar ao se manifestar na sua prática (ARTAUD, 2006, p.89). O teatro, portanto, existe para alertar a todos aqueles que se manifestam através dele que "não somos livres" e que "o céu ainda pode desabar sobre nossas cabeças" (p.89). Por isso, o teatro engajado apresenta-se em toda a sua fragilidade potencial como forma capaz de promover a abertura de outras chaves de leitura dos tempos, seus aspectos estéticos, sociais e políticos.

Em Plínio Marcos, a poética da rebeldia manifestou-se através de um discurso da violência sem o qual a referida poética não se apresentaria como concebida aqui. Como em Artaud, a violência em Plínio Marcos é preponderante como aspecto estético que preconiza a leitura de uma realidade social, notadamente dos personagens marginalizados preconizados pelo autor. É exatamente pelo entendimento deste discurso grotesco da violência no espaço urbano que a poética 
da rebeldia ganha força sem, em nenhum de seus aspectos, ser interpretada como esforço estetizante de uma realidade. Pelo contrário, o que se apresenta é uma tentativa estética não-estetizante de apreensão das sensibilidades "envolvidas no teatro como um turbilhão de forças superiores" (ARTAUD, 2006, p.93). Do ponto de vista da compreensão do teatro como prática propositiva de formulações possíveis, o ideário desta modalidade artística está mais próximo da provocação organizada em signos teatrais, capaz de promover uma reverberação em uma prática nos diversos campos sociais. 0 propósito é banir um suposto estado de paralisia geral, "em vez de continuar a reclamar desse marasmo e do tédio, da inércia e da imbecilidade de tudo" (ARTAUD, 2006, p.93). A palavra mais imediatamente próxima da rebeldia no teatro pode ser assimilada como sendo a ação. A insubmissão no campo artístico tem seu valor aumentado quando ela serve à ação na vida cotidiana. Assim, a qualificação mais oportuna que 0 teatro pode ter, vincula-se a uma prática "violenta e imediata", como desejou Artaud (2006, p.95).

É fundamental ao teatro em sua vertente rebelde uma reverberação no campo social que seja capaz de promover a referida ação, anteriormente mencionada. Este teatro deve provocar uma espécie de eco que se aproxime de algo efetivo, maiormente diante de tempos nos quais o autoritarismo ameaça a liberdade de livre veiculação de ideias. Diante da "instabilidade dos tempos" (p.96) preconizada por Artaud, cabe ao teatro buscar sua ligação com o que pode se aproximar da revolta - como preconizada por Camus - ou da crueldade. Logo, a poética da rebeldia configura-se em sua plenitude quando leva à ação, seja do ponto de vista gregário ou individual. $\mathrm{O}$ que tenho aqui defendido, significa que a busca de direcionamentos no campo da agenda política e estética, para que atinja a sua função como prática insubmissa, pode partir tanto de uma ação coletiva quanto uma ação individual posto que ambas são ações na mesma medida. Evidentemente, a visada aqui empreendida sobre o teatro $e$ sobre a poética da rebeldia compreende 0 primeiro como prática cuja comunicação com o tempo presente se impõe, tendo a visão possível do que são os desafios apresentados por ele. Equivaleria a questionar a necessidade do teatro: a que ele serve? A poética da rebeldia se apresenta como uma espécie de resposta acerca da necessidade do teatro.

O teatro aqui abordado pretende, do ponto de vista ideal, questionar o tempo, mas também os homens e mulheres diante da realidade vivida. Essa tarefa nem sempre é empreendida a partir da aceitação por parte do público. Se o teatro é "sanguinário e desumano" (ARTAUD, 2006, p.105), não é de sua alçada facilitar pelo abrandamento a sua forma e o seu conteúdo, necessários para a sua apreensão por parte dos espectadores. É exatamente esse o sentido do questionamento que $o$ teatro rebelde $e$ cruel pretende executar, no sentido de fazer do teatro um espaço de comunicação imediata e consequente com o tempo, os 
homens, as mulheres e o "sentido utópico da vida" (ARTAUD, 2006, p.104).

Diante do exposto até aqui, torna-se evidente que a poética da rebeldia é uma estratégia de abordagem dramatúrgica dentro de um referido panorama histórico cuja base política e ideológica estava calcada na manifestação do autoritarismo institucional. A rebeldia como estratégia poética está distante de ser um ato heróico de um artista que sofreu perseguição por parte da censura ${ }^{1}$. Ela é, além de um princípio artístico, uma modalidade de sobrevivência num contexto de impedimento das liberdades individuais, caracterizando-se como sendo uma resposta de um artista a diversas situações no campo político, que desembocou na constituição de parte de uma obra dramatúrgica, fruto de uma interpretação do seu lugar no tempo. Artaud, ao abordar a estratégia da crueldade em seu teatro, afirma que ela

[...] é antes de mais nada lúcida, é uma espécie de direção rígida, submissa à necessidade. Não há crueldade sem consciência, sem uma espécie de consciência aplicada. É a consciência que dá ao exercício de todo ato da vida sua cor de sangue, sua nuance cruel, pois está claro que a vida é sempre a morte de alguém. (2006, p.118)

De modo semelhante, a rebeldia no teatro de Plínio Marcos foi fruto de uma necessidade histórica e suas demandas mas, também, fruto de uma necessidade

\footnotetext{
1 Segundo Ventura (1988), este dramaturgo detém um record pouco valoroso na história do teatro brasileiro: teve pelo menos 18 de suas peças vetadas pelos órgãos censores.
}

no nível do que considero se tratar de uma possibilidade momentânea, isto é, agir como garantia de sua sobrevivência enquanto artista. Em um tempo no qual o autoritarismo de Estado era a lei permanente, contando com 0 aparato policial e toda a sorte de força institucional, a reação rebelde no campo do teatro pliniano manifestou-se dentro das possibilidades de um autor que encontrou no naturalismo tardio uma forma de expressão que, aliás, veio a fundir-se com os fundamentos do teatro engajado produzido durante os anos de 1960 no Brasil. Em vista disso, quando a ditadura e a censura se estabeleceram como forças de repressão, a rebeldia se apresentou com a função de coagular um conjunto dramatúrgico que representa a plataforma de princípios do teatro de Plínio Marcos.

A rebeldia em Plínio Marcos se configura, ainda, a partir do recorte temático do conjunto de suas peças aqui privilegiado; os marginalizados são os protagonistas de suas reportagens de um tempo mau. Entretanto, como sugere Artaud (2006, p.136), o mais relevante em considerar os fenômenos do presente está na sua capacidade de mexer no "estado de ebulição moral" dos espíritos do seu tempo. No momento em que o autor santista se notabilizou como autor dramático, o teatro demonstrava um forte apelo à prerrogativa do engajamento social e política, sendo que as formas afastadas dessa modalidade eram - em certa medida - ignoradas pela classe artística de esquerda, sendo consideradas matérias afastadas das questões da atualidade. Portanto, o teatro considerado vivo, verdadeiro, efervescente e fruto de uma "emanação perpétua" 
(ARTAUD, 2006, p.134) dos desafios do tempo presente, era 0 teatro que carregasse em si, em algum grau, a rebeldia como mola propulsora.

\section{Revolução social e revolução cultural}

$O$ teatro aqui referido se distingue por ser 0 representante da revolta como forma estética, no caso, em forma de texto dramático - frente a um determinado panorama politicamente autoritário forçado a uma adequação frente à uma realidade ideológica específica. Ao mesmo tempo, ele apresenta-se como sendo "um grito orgânico"2 (ARTAUD, 2007, p.9) dos homens e mulheres, como reação contra a coerção sofrida, especialmente em tempos nos quais a liberdade de expressão se fragiliza. Em outros termos, o grito a que Artaud alude, se manifesta contra o paternalismo do Estado diante das artes do espetáculo, característica esta que, sob o pretexto de ato "corretivo" e "didático" - por si só pressupostos que rebaixam a arte se investem do aparato policial para mostrar a sua força, a exemplo da censura teatral do Brasil antes e durante o regime de 1964. A arte, como engajamento, investe-se contra as diversas formas de imposição paternalista que se apresente em forma de ideias e ações muitas vezes travestidas de uma suposta intencionalidade positiva. Para Artaud (2007), o tripé da "velha sociedade patriarcal" está baseado nas entidades "pai,

2 O texto original de Artaud (2007) diz: "un cri organique de l'homme" (p.9). pátria, patrão"3 (p.11). Perpassa a tarefa do engajamento a problematização do referido tripé entendido como sendo os fundamentadores de valores cujo fito é o estabelecimento da coerção, em geral a partir de um simulacro benevolente que, no fundo, resguarda as vilezas ardis ordinárias dos comportamentos das classes detentoras do poder.

Destarte, ignorar o tempo presente e suas demandas pode significar o esquecimento do papel da arte como engajamento, uma vez que os intelectuais e os artistas estão, à sua revelia, atrelados ao seu tempo. Esse é um dos vieses interpretativos levantados acerca da obra pliniana escrita entre 1958 e 1969: refletir sobre um artista avaliando a sua concepção estética como sendo inseparável do seu entorno social. Essa perspectiva refere-se à estreita relação entre tempos históricos e concepção poética: ambos os elementos entrecruzamse, gerando ideias e formas que representam leituras de um tempo. Por seu turno, Artaud (2007) sugere que existem armadilhas nessa relação tempo/artista/ação (que aqui tenho interpretado como sendo ação engajada ideologicamente), uma vez que a ação, como necessidade das demandas do tempo, pode se configurar como ação de baixo calibre, a que o encenador francês chama de "prostituição da ação"4 (p.20), principalmente pela cooptação da

\footnotetext{
${ }^{3}$ No original: "Père, patrie, patron, telle est la trilogie que sert de base à la vieille societé patriarcale et, aujhurd'hui, à la chinnerie fasciste" ARTAUD, 2007, p.11).

4 No original: "Mais pour eux cette idée d'une action nécessaire nem veut pas dire prostitution de l'action" (ARTAUD, 2007, p.20).
} 
propaganda enganosa dos discursos facilmente assimiláveis. Ou melhor, ser responsável do ponto de vista da ação diante do mundo e do tempo presente, não significa agir a despeito do conjunto social, muito menos agir cegamente como fruto de uma atitude heróica. Em muitos contextos, este pode ser um comportamento de adequação submissa, em detrimento de uma ação rebelde coerente com os desafios impostos pelo corpo social. Não há, segundo a visada artaudiana, outra forma de "pertencer à sua época" - que esteja para além da entrega à "especulação pura" -, que não seja promovendo a guerra ${ }^{5}$ (ARTAUD, 2007, p.39) contra o engodo da letargia inoperante da paz da torre de marfim. Em vista disso, toda criação é um ato de guerra: "criar em paz é uma atitude burguesa [...]. A fome, o frio, o amor, a doença e o sono não são coisas das quais podemos tirar um prazer artístico. Não sou a favor de que os artistas obtenham prazeres artísticos ao preço do frio, da fome, do sono"6 (ARTAUD, 2007, p.141). É a partir desta perspectiva que o encenador francês concebe o papel dos artistas na sociedade, distante do ideal individualista desagregador.

\footnotetext{
${ }^{5}$ No original: "Il y a dix mille façons de s'occuper de la vie et d'appartenir à son époque. Nous ne sommes pas pour que dans um monde désorganisé les intellectuels se livrent à la spéculation pure. Et la tour d'ivoire nous ne savons plus ce que c'est. Nous sommes pour que les intellectuels entrent eux aussi dans leur époque; mais nous ne penson pas qu'ils y puissent entrer autremente qu'en lui faisant la guerre" (ARTAUD, 2007, p.39).

6 No original: "[...] Créer em paix est une attitude bourgeoise, et si je suis contre toutes les attitudes bourgoises c'est parce que j'ai une notion véritable de l'esprit de la proprieté. La faim, le froid, l'amour, la maladie et le sommeil ne sont pas des choses desquelles on peut tire une jouissance artistique. Je ne suis pas pour que les artistes se procurent des jouissances artistiques au prix du froid, de la faim, du sommeil. (ARTAUD, 2007, p.141).
}

Nesse contexto, os artistas configuram-se como sendo aqueles sujeitos capazes de, conhecendo sua época, dar respostas aquilo que se vê, se ouve e se sente. $\mathrm{Na}$ concepção de Artaud, o artista digno desse nome é aquele que não ignora sua função social, manifestada no dever de "fazer cair sobre os seus ombros os cóleras errantes da época para descarregá-la de seu mal estar psicológico"7 (2007, p.135). A reflexão devolve aos artistas aquela função que, de algum modo, sempre lhes pertenceu: a sua posição de potenciais mobilizadores sociais, no sentido de promoção da desordem em sua vertente provocativa. São eles os espectadores privilegiados do tempo, sendo ainda mais privilegiados pela sua capacidade de ação consequente.

No debate político da primeira metade do século XX - que no Brasil se estendeu até os anos de 1970 -, as discussões em torno da revolução social eram recorrentes e fruto de diversas coalizões ideológicas girando a partir de diversas tendências dentro do mesmo tema. Entretanto, a revolução social foi preferencialmente concebido como sendo a grande pedra de toque da mudança fundamental sem que fossem problematizados outros aspectos deste mesmo problema, notadamente, a revolução cultural. Artaud (2007) preconizou a indissociabilidade de uma à outra, isto é, a revolução social não acontecerá em sua plenitude sem a revolução no campo cultural. A revolução, para ser profunda e ampla, deve ser empreendida no campo da cultura e não apenas no nível social e econômico, em

\footnotetext{
7 No original: "[...] de faire tomber sur ses épaules les colères errantes de l'époque pour la décharger de son mal-être psychologique [...]" (ARTAUD, 2007, p.135).
} 
detrimento da anterior. A mudança revolucionária na cultura empreende uma revolução no nível da consciência frente ao mundo. Artaud (2007), mais radicalmente, considera que a ideia que aparta os problemas da vida prática mais imediata (tomando o discurso econômico e social ordinários) das da cultura, da natureza, do corpo, do espírito e da mente, tem sua origem em uma concepção burguesa de revolução ${ }^{8}$.

O teatro é aqui refletido como sendo idealmente capaz de promover algum tipo de revolução no sentido artaudiano (2007, p.122). O reconhecimento desta arte como campo de atuação no nível político política, foi bastante estimulado dentro da geração a qual Plínio Marcos pertenceu. $O$ engajamento pretendido por uma arte que poderia atingir e modificar tanto quem 0 executa quanto quem o assiste, fez dessa arte um instrumento de experimentação, também, no campo político. Durante o século $X X$, essas manifestações ideológicas do teatro perpassaram praticamente todos os agrupamentos estéticos, desde Artaud, ao engajamento dos coletivos contemporâneos, passando pelas experimentações modernizantes do teatro na Europa da virada do século XIX/XX. A perspectiva do teatro como ação política tornou esta arte, no Brasil dos anos de 1960, uma das mais visadas pela censura, fato este que traz à tona a visão

${ }^{8}$ No original: "C'est pour moi une idée bourgeoise celle qui sépare le problème de la vie du problème de la culture, le problème de la vie dans l'homme du problème de la vie dans la nature, le problème du corps du problème de l'esprit, et les problèmes des maladies physiologiques des problèmes des maladies mentales" (ARTAUD, 2007, p.144-145). do teatro sustentada por outros regimes autoritários ao longo do último século (ao menos), que variam da cooptação como ferramenta em favor de regimes de exceção - demonstrando um entendimento do teatro como aliado na manutenção da visão adotada pelos detentores do poder -, até a perseguição policialesca como a que a geração de artistas pós-1964 viveu em nosso país, no qual a visão do teatro mantinha-se como elemento de natureza subversiva, mobilizador de massas contra o poder instituído.

O que a ditadura e a sua censura conseguiram promover, em termos de resposta ideológica da classe artística no Brasil, foi a busca de novos rumos de insubmissão possível. É justamente nesse sentido que a obra de Plínio Marcos tem sido abordada aqui, considerando seus aspectos estéticos que agregaram novos temas à dramaturgia brasileira, mas, também, considerando a constituição ideológica do sujeito rebelde que ele, por vezes, compulsoriamente foi. Se, como sugere Contreras, Maia e Pinheiro (2002, p.12), "o dramático é um ato espontâneo" na obra pliniana, isto se dá como fruto da busca da compreensão de uma realidade abordada em cena sem os filtros que até então eram utilizados como abrandadores do cruel universo revelado em forma esteticamente organizada. Por isso mesmo, as peças de Plínio Marcos que compõem a poética rebelde, provocam reflexão pela dramaticidade alcançada, aliado aos temas que, mesmo nos dias de hoje, mantém sua atualidade. Mesmo a solução em geral encontrada por Plínio Marcos para os seus 
dramas, não aceita "compromisso ou acomodamento de situações, apenas um rompimento dos vínculos, a morte ou a supressão de uma das partes geradoras de tensão" (CONTRERAS, MAIA e PINHEIRO, 2002, p.13). A solução encontrada por aqueles a quem tudo é negado, é o seu próprio apagamento, a sua extinção, a sua eliminação. Em certa medida, esta resolutiva se adéqua ao próprio modo como Plínio Marcos produziu suas peças, quase sempre sob a tensa relação com a censura teatral. Sua dramaturgia considerou o presente mais imediato como objeto de análise estética, mas guardou um valor para o futuro, uma vez que o debate sobre as injustiças e a marginalização de contingentes populacionais constituía temática de última hora. A sugestão de futuro foi apreendida, por exemplo, pelo cineasta José Joffily em seu filme, baseado na peça homônima, embora grafado diversamente, 2 perdidos numa noite suja, que representou os dois protagonistas como imigrantes em Nova lorque: dois representantes da subcidadania brasileira, extraviados compulsoriamente para uma vida nas quebradas da América do Norte.

A dramaturgia de Plínio Marcos, com suas polêmicas e controvérsias, corresponde a uma produção teatral em uma época de acirramentos, sobretudo no âmbito políticos. Sua visão de mundo reverbera este lugar de autor dramático de um tempo mau, em alusão a alcunha que recebeu da crítica teatral. Em vista disso, a própria construção de si como sendo uma personagem marginal, representa no dizer do poeta Glauco Mattoso, "uma recusa de todos os modelos estéticos rigorosos, seja eles tradicionais ou de vanguarda". Do mesmo modo, Plínio Marcos demonstrou, em sua investigação do universo dos párias da sociedade, um esforço deliberado ou compulsório de identificação com uma postura "antiintelectual" e "antiliterária" (MATTOSO apud CONTRERAS, MAIA e PINHEIRO, 2002, p.32).

Como tônica recorrente nas reflexões do autor santista está a possibilidade de interferência na liberdade de expressão no que tange seu trabalho e dos demais artistas do palco. Sobre este aspecto, o dramaturgo insistiu em diversas ocasiões, como na crônica intitulada Um saltimbanco em busca do seu povo, publicada no jornal Folha de São Paulo em julho de 1977. O dramaturgo repetia-se em relação ao seu desejo de tornar "o palco brasileiro [...] uma tribuna livre onde se pudesse discutir até as últimas consequências os problemas do homem" (MARCOS, 2002, p.127). Esta foi uma de suas bandeiras, condicionada pelo grau de distorção que parte de sua obra sofreu, ao menos nos termos da interpretação praticada pelos órgãos de repressão e censura do período militar. 0 sucesso conquistado a partir de 1966, sem a desejada liberdade de expressão representava, na visada pliniana, uma espécie de vazio improdutivo, visto que ser reconhecido sem a possibilidade de respeito à sua criação teria valor limitado como conquista. O dramaturgo reconhece os frutos que o seu trabalho lhe rendeu, entretanto nega os mencionados proveitos impondo-se como ação considerar os louros conquistados como sendo inviáveis "enquanto não houver justiça" e "liberdade de expressão no solo onde criarei meus filhos [...]" (MARCOS, 2002, p.129). A crítica pliniana recai sobre aquilo que ele 
chama de "inversão de valores", isto é, a mudança, por oportunismo, de um ideal compreendido como sendo importante de ser sustentado. Como exemplo abordado em crônica não publicada intitulada Desabafo, o desvirtuamento do palco em prática que desabona a atividade teatral, segundo o autor, representa um desacordo entre aquilo que ele concebia como prática de liberdade em cena e aquilo que seria a manifestação da "artimanha" no palco (MARCOS, 2002, p.134).

Por outro lado, a afirmação pliniana de uma leitura do corpo social e suas mazelas mormente os marginalizados e marginalizadas urbanos - tem como base certo nível de um altruísmo importante de ser notado. A subjetividade que the foi possível compor encontrou no teatro um projeto poético que aqui tenho atribuído à rebeldia como princípio. Como manifestação disso, e diante do choque provocado pelos crescentes índices de violência na cidade de São Paulo, o dramaturgo escreveu em crônica censurada intitulada Espiando a violência das grandes cidades que:

Os mortos brasileiros não foram inventados por mim. Nem sou eu que estou inventando quando digo que o povão lesado das quebradas do mundaréu está se tratando com mingau de araruta feito com leite de sapo e comendo capim amargo pela raiz. Tem muita gente que mora nas beiras do rio e quase se afoga toda vez que chove. Tem muita gente cansada de berrar da geral sem nunca influir no resultado. Pra essa gente, petróleo, contrato de risco, não quer dizer nada. O que lhes diz é a fome, má conselheira, que induz a besteiras, a violências inúteis, a gestos desesperados. Não será a miséria que está por trás desses crimes todos nas grandes cidades? Vai ver que é (MARCOS, 2002, p.137-138).

O dramaturgo aborda o tema da violência a partir de uma visada que tem acordo em diversos autores especialistas no tema. A abordagem de suas personagens segue 0 raciocínio demonstrado pelo autor: uma sociedade que promove a injustiça e as desigualdades gera frutos que correspondem àquilo que a sociedade, de certo modo, lhe possibilitou ser. A marginalização provocada pela miséria, portanto, segundo a perspectiva pliniana, condiciona parte das mazelas sofridas pelo corpo social. As dramaturgias de Plínio Marcos evidenciam esta perspectiva. Este mesmo tema foi abordado pelo dramaturgo em sua crônica Queremos uma lei santa, publicada no jornal Última Hora, em maio de 1969, na qual o autor critica, genericamente, os comportamentos irresponsáveis diante da existência alheia, por parte de quem "se encolhe nas moitas e fica espiando o lance" e que "Não assume nenhuma responsabilidade com 0 próximo" (MARCOS, 2002, p.139). A crítica à apatia de determinada qualidade de cidadania desvela uma parte do pensamento social de Plínio Marcos, cuja reverberação teve em sua dramaturgia um mote de investigação e, em igual medida, em sua obra romanesca e contista (que ainda estão por serem estudadas com profundidade). 
O teatro brasileiro durante os anos de 1960 lutava em diversas correntes, contra uma compreensão fatalista e determinista da realidade de então. Este fato coloca 0 teatro em conformidade com o desejo coletivo de luta contra 0 destino predestinado, principalmente no que diz respeito à realidade social do país, grande pauta do teatro engajado daquele período. Destarte, o teatro de Plínio Marcos e sua poética da rebeldia, nos termos artaudianos, pode ser caracterizado como sendo aquele "da revolta humana que não aceita a lei do destino, um teatro repleto de gritos que não são de medo mas de raiva, ainda mais que de raiva, do sentimento do valor da vida"9 (ARTAUD, 2007, p.70). É papel da arte, como sustento, construir com desvendamento da vida em sociedade, no sentido de tentar construir uma ordem cuja base seja a justiça, direito humano fundamental. Evidentemente, este papel cabe àquele teatro que se conceba como pertencente a uma sociedade contraditória e com desafios a serem superados. contrário disso seria aquele teatro a serviço do que Artaud chama de "capitalismo da consciência"10 (2007, p.86), do qual o ideal é imediatamente cooptado pelo pragmatismo hegemônico.

Para Artaud (2007, p.117), a "destruição é transformadora"11. Os homens de teatro aqui evidenciados representam desejos de

\footnotetext{
${ }^{9}$ No texto original: "C'est le théâtre de la révolte humaine qui n'accepte pas la loi du destin, c'est um théâtre rempli de cris qui ne sont pas de peur mais de rage, et encore plus que de rage, du sentiment de la valeur de la vie" (ARTAUD, 2007, p.70).

${ }^{10}$ No original: "[...] à cette forme redoutable du capitalisme que moi, j'appelle le capitalisme de la conscience puisque l'âme c'est le bien de tous" (ARTAUD, 2007, p.86).

${ }^{11}$ No original: "[...] Mais la destruction est transformatrice. La vie maintient as continuité par la transformation des apparences de l'être" (ARTAUD, 2007, p.117).
}

imersão nas questões de natureza social e da própria visão sobre a estética, a partir de um viés marcadamente politizado do campo progressista (termo que aqui se contrapõe a retrocesso). A destruição pode ser capaz de transformar quando a reconstrução se faz pela via da reformulação de princípios que, idealmente, devem buscar na coerência o seu tratamento. Essa pode ser considerada uma base para a mencionada revolução cultural/social aludida por Artaud (2007), que significa, em outros termos, a renovação da ideia de que os homens e as mulheres estão para além da ordinária visão que preconiza a força de trabalho em detrimento do ente humano. Nesse sentido, é preciso despragmatizar para que novas formas tanto de teatro quanto de homens e mulheres sejam capazes de emergir para transformar a arte e a sociedade. A visada rebelde sobre o mundo apresenta-se como uma proposição de ação no contexto da obra de Plínio Marcos, portanto, como um duplo do teatro, parafraseando Artaud (2006). Teatro e rebeldia são, no contexto aqui abordado, o duplo um do outro, dos quais a natureza é demonstrada pelas formas de resistências possíveis em contextos de liberdade assistida ou mesmo de interdição das liberdades individuais e criativas.

Recebido em 26/04/2018

Aceito em 05/07/2018

\section{Referências Bibliográficas}

ARAÚJO, Gessé Almeida. A violência na obra de Plínio Marcos : Barrela e Navalha na carne. Salvador : EDUFBA, 2015. 
ARISTÓTELES. Poética. Tradução: Eurodo de Souza. São Paulo: Nova Cultural/Coleção Pensadores, 1991.

ARTAUD, Antonin. Messages révolutionnaires. Paris: Folio essais, 2007.

ARTAUD, Antonin. 0 teatro e seu Duplo. São Paulo: Martins Fontes, 2006.

CONTRERAS, Javier Arancibia; MAIA, Fred; PINHEIRO, Vinícius. Plínio Marcos: a crônica dos que não têm voz. São Paulo: Boitempo Editorial, 2002.

MARCOS, Plínio. Chapéu em cima de paralelepípedo para alguém chutar. São Paulo: versão digitalizada, 1966.

MARCOS, Plínio. Dois perdidos numa noite suja. São Paulo: versão digitalizada,1966.

MARCOS, Plínio. Espiando a violência das grandes cidades. In: CONTRERAS, Javier Arancibia; MAIA, Fred; PINHEIRO, Vinícius. Plínio Marcos: a crônica dos que não têm voz. São Paulo: Boitempo Editorial, 2002.

MARCOS, Plínio. Eu queria humanizar o exército. In: CARVALHO, Sérgio de; ROCHA, Érika. 1a Feira Paulista de Opinião. São Paulo: Expressão popular, 2016.

MARCOS, Plínio. Figurinha difícil: pornografando e subvertendo. São Paulo: Editora SENAC-São Paulo, 1996.

MARCOS, Plínio. Histórias das quebradas do mundaréu. São Paulo: Miriam Paglia Editora de Cultura, 2004.

MARCOS, Plínio. Homens de papel. Edição do autor: São Paulo, 1984.

MARCOS, Plínio. Melhor Teatro (Coleção). Seleção e prefácio: llka Marinho Zanotto. São Paulo: Global, 2003.

MARCOS, Plínio. Na rua alguém me abraça: o censor da peça que escrevi. In: CONTRERAS, Javier Arancibia; MAIA, Fred; PINHEIRO, Vinícius. Plínio Marcos: a crônica dos que não têm voz. São Paulo: Boitempo Editorial, 2002.
MARCOS, Plínio. Neste domingo me confesso. In: CONTRERAS, Javier Arancibia; MAIA, Fred; PINHEIRO, Vinícius. Plínio Marcos: a crônica dos que não têm voz. São Paulo: Boitempo Editorial, 2002.

MARCOS, Plínio. Oração para um pé-dechinelo. Salvador: Banco de textos, Escola de Teatro da UFBA (Sem data).

MARCOS, Plínio. Os fantoches. São Paulo: versão digitalizada,1963.

MARCOS, Plínio. Quando os navios atracam. São Paulo: versão digitalizada,1965.

MARCOS, Plínio. Queremos uma lei santa. In: CONTRERAS, Javier Arancibia; MAIA, Fred; PINHEIRO, Vinícius. Plínio Marcos: a crônica dos que não têm voz. São Paulo: Boitempo Editorial, 2002.

MARCOS, Plínio. Reportagem de um tempo mau. São Paulo: versão digitalizada,1963.

MARCOS, Plínio. Sou o analfabeto mais premiado do país (entrevista). Revista Realidade, Ano 3, número 30. Setembro, 1968.

MARCOS, Plínio. Um saltimbanco em busca do seu povo. In: CONTRERAS, Javier Arancibia; MAIA, Fred; PINHEIRO, Vinícius. Plínio Marcos: a crônica dos que não têm voz. São Paulo: Boitempo Editorial, 2002.

MARCOS, Plínio. Verde que te quero verde. In: CARVALHO, Sérgio de; ROCHA, Érika. 1a Feira Paulista de Opinião. São Paulo: Expressão popular, 2016.

PAREYSON, Luigi. Os Problemas da estética. Tradução: Maria Helena Nery Garcez. São Paulo: Martins Fontes, 1997.

UBERSFELD, Anne. Para ler o teatro. Tradução de José Simões. São Paulo: Perspectiva, 2005.

VENTURA, Zuenir. 1968, o ano que não terminou: a aventura de uma geração. Rio de Janeiro: Nova fronteira, 1988. 
moringa 